\title{
Surgery Management of Giant Serpentine Aneurysm: A Case Report and Literature Review
}

\author{
Bo Zhou ${ }^{\mathrm{a}}$, Chao You ${ }^{\mathrm{a}, \mathrm{b}}$
}

\begin{abstract}
We report a case of giant serpentine aneurysm (GSA) of the right middle cerebral artery (MCA) that successfully treated by an extracranial to intracranial (ECA/ICA) bypass with a graft from the superficial temporal artery of the external carotid artery to a temporal lobe branch of the middle cerebral artery. The patient was a 36 years old man who presented to our hospital with an acute headache. CT and MR examinations revealed a large serpentine aneurysm arising from right MCA. Angiography demonstrated a GSA. After revascularization, the patient obtained a very good outcome.
\end{abstract}

Keywords: Giant serpentine aneurysms; Treatment

\section{Introduction}

Giant serpentine aneurysms (GSAs) are rare, fusiform aneurysms greater than $2.5 \mathrm{~cm}$, which have a characteristic serpiginous patent channel coursing in the DSA paragraph [1]. Which were first documented by Segal and Mclaurin [2].Treatment of giant serpentine aneruysms should be individualized due to the complex and varied hemodynamics and morphological features. Prior to the use of revascularization surgery in the neurosurgical field, surgical treatment of giant serpentine aneurysms was associated with unacceptable morbidity and mortality rates as high as 33\%[3, 4].

Manuscript accepted for publication September 1, 2011

${ }^{\mathrm{a}}$ Department of Neurosurgery, West China Hospital, Sichuan University, \# 37 Guoxue Road, Chengdu City, 610041, PR China

bCorresponding author: Chao You. Email: youchao618@gmail.com

doi:10.4021/jmc288e
We report a case of a giant serpentine aneurysm of the right middle cerebral artery (MCA). Treatment involved a superficial temporal artery (STA-MCA) bypass and resection of the aneurysm. 8 months later follow up show the patient obtained a very good outcome.

\section{Case Report}

A 36-year-old man was brought to our hospital with a 4 days history of headache. Physical examination revealed normal neurological function. CT, MRI, MRA and DSA revealed a right middle cerebral artery segment giant serpentine aneurysm (Fig. 1A, B, C, D, E). We then performed a resection of the giant aneurysm and an extracranial to intracranial (ECA/ ICA) bypass with a graft from the superficial temporal artery of the external carotid artery to a temporal lobe branch of the middle cerebral artery. Intraoperative micro-Doppler studies demonstrated that flow within the middle cerebral artery branches was adequate. 8 months later DSA follow-up showed a successful EC/IC bypass (Fig. 1F, Arrow) and the patient headache disappeared with no obvious neurological deficit.

\section{Discussion}

Giant serpentine aneruysms form a subgroup of large intracranial aneurysms that have characteristic computed tomography (CT), magnetic resonance (MR), and angiographic features [5]. Giant serpentine aneurysms usually present with serizures or a progressive neurologic deficits related to increasing intracranial mass effect and adjacent edema. Tomasello et al [6] reported the progression over 5 years of a small fusiform aneruysm of branch of the middle cerebral artery into a giant serpentine aneurysm, suggesting that the latter may have its origin in fusiform aneruysms that grow larger in time and undergo thrombosis and organization.

Pathologically, surgically resected giant serpentine aneurysms show a thick fibrous wall surrounding old laminated clots with attempts at recanalization. The wall of the aneruysm contains neovessels, deposits of hemosiderin, and 


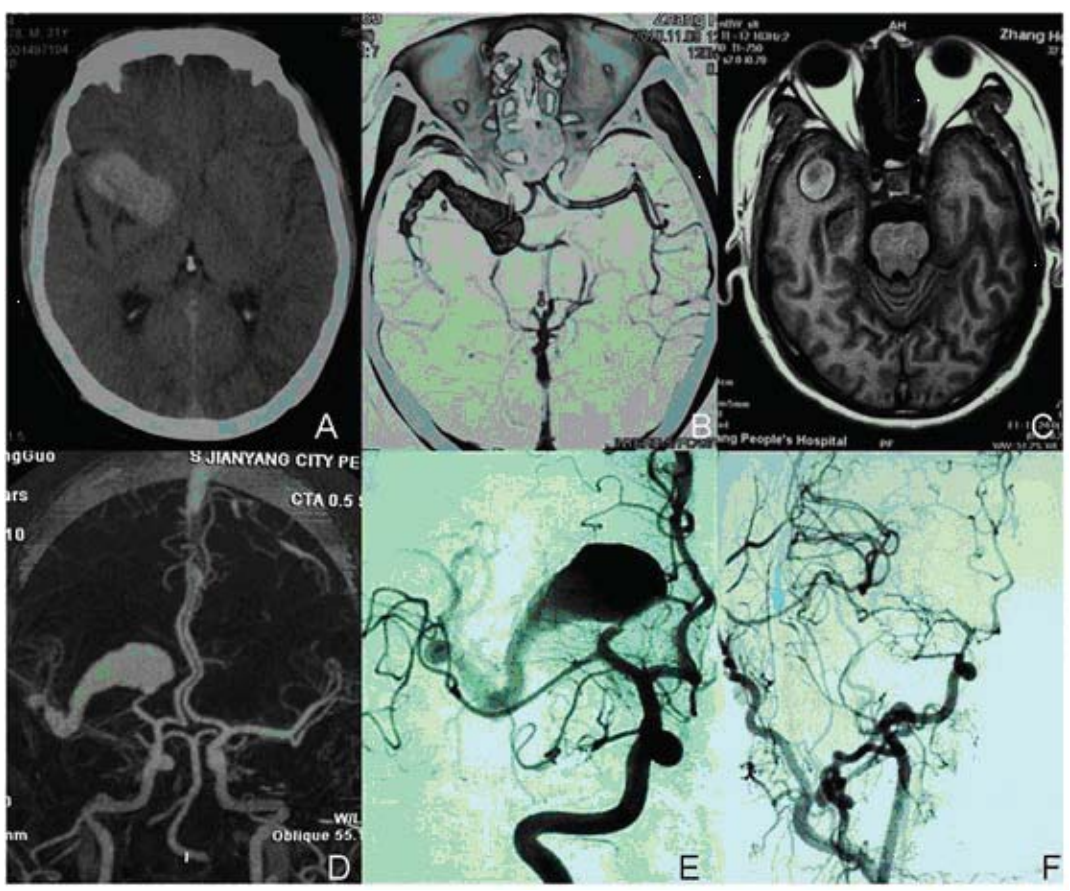

Figure 1. Coronal CT scan revealed in temporal lobe occupying lesion (A). T1 coronal MRI scan revealed a heterogeneous mass occupying lesion (C). CTA, MRA and DSA revealed a right MCA segment giant serpentine aneurysm (B, D, E). The arrow show a successful EC/IC bypass $(F)$.

calcifications [7].

Cerebral angiography establishes the diagnosis of giant serpentine aneurysms and provides the anatomic detail necessary for their treatment. In the past, no surgical therapy could be offered to such kind of patients. Now, the feeding parent vessel can be sacrificed proximal to the giant serpentine aneurysms, keep vascular supply to the distal territory through surgical anastomosis. The treatment of giant serpentine aneurysms should aim to eliminate the mass effect and keep the circulation to the distal arterial territory. This can be best achieved by perform a surgical revascularization procedure of the distal territory with resection of the aneurysm.

\section{Conclusions}

Treatment of giant intracranial aneurysms especially in the MCA (middle cerebral artery) showed obtain a good outcome after emerge of the revascularization technology. The vessel surgery will play a more and more important role in the treatment of giant intracranial aneurysms [8].

\section{Acknowledgements}

This paper was surported by National Natural Science Foundation of China (No.20801185 and No.30872673)

\section{References}

1. Aletich VA, Debrun GM, Monsein LH, Nauta HJ, Spetzler RF. Giant serpentine aneurysms: a review and presentation of five cases. AJNR Am J Neuroradiol. 1995;16(5):1061-1072.

2. Sari A, Kandemir S, Kuzeyli K, Dinc H. Giant serpentine aneurysm with acute spontaneous complete thrombosis. AJNR Am J Neuroradiol. 2006;27(4):766768.

3. Albrecht S, Kahn HJ. Immunohistochemistry of intravascular papillary endothelial hyperplasia. J Cutan Pathol. 1990;17(1):16-21.

4. Chen TJ, Kuo T. Giant intracranial Masson's hemangioma. Report of a fatal case. Arch Pathol Lab Med. 1984;108(7):555-556.

5. Mawad ME, Klucznik RP. Giant serpentine aneurysms: radiographic features and endovascular treatment. AJNR Am J Neuroradiol. 1995;16(5):1053-1060.

6. Tomasello F, Albanese V, Cioffi FA. Giant serpentine aneurysms: a separate entity. Surg Neurol. 1979;12(5):429432.

7. Belec L, Cesaro P, Brugieres P, Gray F. Tumor-simulating giant serpentine aneurysm of the posterior cerebral artery. Surg Neurol. 1988;29(3):210-215.

8. Scozzafava J, Sutherland G. Giant intracranial aneurysm. CMAJ. 2011;183(9):E604. 